\title{
Efeitos de Duas Modalidades Tutoriais para a Criança Tutora em Tarefas Espaciais
}

\section{Effects of Two Tutorial Modalities on Tutor Children in Spatial Tasks}

\author{
Irene Franciscato ${ }^{a} \&$ Maria Regina Maluf ${ }^{b^{*}}$ \\ ${ }^{a}$ Faculdade de São Bernardo do Campo, São Bernardo do Campo, Brasil e Faculdades Oswaldo Cruz, São Paulo, Brasil \\ ${ }^{b}$ Pontifícia Universidade Católica de São Paulo, São Paulo, Brasil e Universidade de São Paulo, São Paulo, Brasil
}

\begin{abstract}
Resumo
O estudo investiga efeitos da tutoria para o tutor, na aprendizagem de noções espaciais, em duas modalidades: explicação oral e explicação oral com demonstração. Participaram 40 crianças de 8 a 9 anos, em três grupos experimentais e um grupo controle. A pesquisa teve delineamento experimental, com pré-teste e pós-testes. No pré-teste e pós-testes 1 e 2 foram aplicadas duas provas de noções espaciais. A tarefa experimental consistiu na realização do jogo do parking em três condições: crianças sozinhas, crianças em díades na modalidade explicação oral ou na modalidade explicação oral com demonstração. Os resultados mostraram que a tutoria favoreceu a aprendizagem das noções espaciais para a criança tutora, com vantagem para a modalidade explicação oral com demonstração. Foram identificadas variações nos progressos alcançados pelos tutores nas duas modalidades tutoriais. São feitas considerações sobre as vantagens da tutoria no campo educacional. Palavras-chave: Tutoria; criança tutora; interação criança-criança; aprendizagem de noções espaciais.
\end{abstract}

\begin{abstract}
The study concerns the effects of tutoring on tutor children, on the learning of spatial notions, in two tutorship modalities, oral explanation and oral explanation with demonstration. Subjects were 40 children aged 8 to 9 years old, randomly assigned to three experimental groups and a control group. The study design is experimental, with pre-test and post-test. Two spatial tasks were employed as pre-test and post-tests $(1$ and 2). The experimental task consisted in a parking game carried out under three conditions: children alone, children in pairs for both oral explanation and oral explanation with demonstration. Results showed that tutor's learning on the focused spatial notions was favored by tutorship especially under the oral explanation with demonstration condition. Some variations on the tutor's progress were also identified on both modalities. The results provide some grounds on which tutorship may be debated in the educational field.

Keywords: Tutorship; tutor children; child-to-child interaction; spatial notions learning.
\end{abstract}

Nos estudos sobre tutoria não encontramos uma definição consensual a respeito do conceito de tutoria ou tutor. Hartup (1983) refere-se à tutoria como sendo um desempenho de crianças semelhante àquele de professores, em diferentes contextos de interação. Barnier (1989, 1994) e Verba (1996) não apresentam uma definição, embora ambos se refiram a pesquisas em que um parceiro orienta outro.

Neste artigo, quando nos referimos à tutoria ou tutor, entendemos ser a interação social em que um indivíduo mais capaz, mais experiente ou mais adiantado na realização de uma tarefa atua com o objetivo de ajudar outro indivíduo, seu parceiro. Este, por sua vez, é menos experiente ou menos adiantado na atividade em torno da qual se exerce a tutoria. As situações de interação de tutela são vistas como benéficas tanto para aquele que ajuda, o tutor, quanto para aquele que é ajudado, o tutorado.

* Endereço para correspondência: Rua Ministro de Godoy, 696, São Paulo, SP, 04530-000. E-mail: marmaluf@ajato.com.br

As autoras agradecem as contribuições de Michel Deleau, Universidade de Rennes2, França, pelas contribuições no desenvolvimento do tema da pesquisa.
O principal objetivo deste estudo é examinar os efeitos da relação de tutoria para a criança tutora, na realização de tarefas que envolvem noções espaciais. A interação entre crianças favorece a autoconfiança e a aquisição de conhecimento, desenvolvendo a capacidade de aprender, como já demonstrado em trabalhos anteriores (Moro, 1991; Nemirovsky, 1992). Outros estudos trataram explicitamente dos efeitos da interação de tutoria para o sujeito tutor (Barnier, 1994; Berzin, 1999; Filippaki, Barnier \& Papamichël, 2001; Gandon-Cretois, 2001). Nessa mesma perspectiva, a tutoria será analisada como um fator de facilitação dos processos de socialização e de aquisição de conhecimentos e não como processo implicado no desenvolvimento cognitivo propriamente dito.

Conforme Barnier (1994), o primórdio da tutoria remonta a pensadores como Sócrates, na Antigüidade, Quintiliano, no século IV e Comenius, no século XVII. Na maiêutica socrática, através do encaminhamento de perguntas pelo sábio ao aprendiz, este avançaria em seu pensamento ao constatar a insuficiência de suas respostas, o que o lançaria a um nível de reflexão anteriormente inexistente. Na recomendação quintiliana, a criança deveria ser ensinada junto a outras crianças, acreditando que 
através da imitação, comparação e auxílio mútuos, as crianças aprenderiam melhor do que quando deixadas sozinhas. Na prescrição de Comenius, referindo-se ao ensino de todos para todos, propõe-se que, complementarmente ao ensino do mestre, os alunos ensinem uns aos outros, pois ao fazerem o papel de mestre instruiriam a si mesmos, apropriando-se efetivamente do saber.

A idéia original da tutoria se manteve, mas sua modalidade sofreu mudanças nos séculos XVI a XVIII, inicialmente em escolas religiosas francesas. Dada a escassez de pessoal preparado para o ensino da leitura e escrita, essas escolas adotaram o pareamento de um tutor para um grupo de estudantes, dando origem à monitoria. Este tipo de pareamento adentra ao século XIX, na Inglaterra, através do Sistema Monitorial de Bell e Lancaster que incluiu rudimentos da aritmética e foi posteriormente difundido em vários países europeus.

Da segunda metade do século XX em diante, programas de ensino como o ASPIRAMACE, nos Estados Unidos e o PERACH, em Israel, sustentaram os benefícios da tutoria para tutores e tutorados (Barnier, 1994). Outras experiências educacionais com a tutoria entre jovens estudantes universitários na Inglaterra (Button, Simns \& White, 1990) e entre crianças, como a de Nemirovsky (1992) na Espanha e a de Finkelsztein e Ducros (1989) na França, retomaram a tutoria como importante estratégia de aprendizagem entre crianças. A experiência realizada com crianças espanholas demonstrou a possibilidade de aplicação de estratégias de tutoria junto a alunos com idades bastante diferenciadas, e a que foi realizada com crianças francesas defendeu o caráter preventivo da tutoria frente ao fracasso escolar.

Mais recentemente, estudos sobre a interação de ajuda e imitação interativa colocaram em evidência as vantagens da tutoria no campo pedagógico (Baldi, 2000; Gartner, Kohler \& Riesmman, 1971; Goodlad \& Hirst, 1989; Winnykamen, 1997, 1998) e outros trabalhos apontaram as vantagens das interações de tutoria para a aceitação social de crianças portadoras de necessidades especiais (Custer \& Osguthorpe, 1983; Fenrick \& Peterson, 1984; Jones, 1988; Shafer, Egel \& Neef, 1984).

Na mesma perspectiva destacam-se também os estudos de Barnier (1989, 1994), realizados com crianças francesas que resolviam tarefas envolvendo noções espaciais. Barnier verificou que a realização das tarefas em parceria, em que a criança tutora orientava verbalmente a criança tutorada, trouxe maiores progressos às crianças tutoras quando comparadas às que executaram sozinhas as mesmas tarefas.

A presente pesquisa, realizada com crianças brasileiras, foi inspirada em Barnier (1989) e introduziu uma segunda condição experimental, designada como orientação verbal acompanhada de demonstração. A decisão de acrescentar às explicações orais a demonstração foi tomada em decorrência de nossa observação empírica e de relatos de pesquisa sobre a interação criança-criança. Conforme nossa observação, crianças interagem orientando suas parceiras enquanto brincam ou enquanto estudam, não só explicando oralmente, como também demonstrando à parceira como proceder para a realização de uma atividade. Em relatos de pesquisas como as de Góes (1995), Oliveira e Rossetti-Ferreira (1993), Perret-Clermont (1978), Verba (1996), além da fala, há freqüentes referências a gestos e demonstrações na interação entre crianças, permitindo interpretar que outros fatores, além da linguagem oral, são determinantes na interação. Observe-se ainda que enquanto para esses pesquisadores a demonstração é considerada apenas implicitamente, Balacheff (1982) a considera como importante condição nas interações no campo do ensino-aprendizagem, especialmente quando noções espaciais estão em jogo.

Portanto, além da condição de explicação oral examinada por Barnier (1989, 1994), a presente pesquisa incluiu mais uma modalidade tutorial, a saber: a criança tutora, além de explicar oralmente, demonstra à parceira como realizar a tarefa.

As hipóteses que direcionaram este trabalho de investigação foram:

1. Crianças tutoras que interagem em díades orientando suas parceiras na realização de uma tarefa espacial, em duas modalidades, a saber, explicação oral versus explicação oral com demonstração, obtêm maiores progressos em noções espaciais quando comparadas a crianças que se exercitam sozinhas.

2. Crianças que tutoram seus parceiros para a realização de uma tarefa espacial segundo a modalidade explicação oral com demonstração, obtêm maiores progressos nas noções espaciais do que as que tutoram na modalidade explicação oral.

Também foi objetivo da pesquisa compreender algumas especificidades da interação entre tutor e tutorado, nas duas modalidades de tutoria.

\section{Método}

\section{Participantes}

Das 177 crianças de $2^{\text {as }}$. e $3^{\text {as }}$. séries do ensino fundamental de uma escola da rede pública, que inicialmente fizeram o pré-teste, foram selecionadas 40 crianças, sendo 20 meninas e 20 meninos, com idade entre oito e nove anos, eliminando-se os extremos de idade. Além da série, idade e equiparação quanto a sexo, utilizou-se como critério de seleção o resultado obtido no pré-teste, a saber, um mínimo de três acertos em pelo menos uma das provas e um máximo de nove acertos nas duas provas do pré-teste.

As crianças selecionadas foram distribuídas aleatoriamente em três grupos experimentais e um grupo controle, cada um deles formado por cinco meninos e cinco meninas:

1. GE I: 10 crianças que realizam o treino (jogo do parking) sozinhas.

2. GE II: 10 crianças tutoras na modalidade 1: explicar oralmente ao parceiro como realizar a tarefa.

3. GE III: 10 crianças tutoras na modalidade 2: explicar oralmente e demonstrar ao parceiro como realizar a tarefa.

4. GC: 10 crianças que não realizam o treino. 
Foram colocadas na condição de tutoradas 20 crianças que freqüentavam a primeira série da mesma escola, sendo 10 meninas e 10 meninos, com idade entre 6 e 7 anos, eliminando-se os extremos de idade. As díades tutortutorado foram constituídas com crianças do mesmo sexo.

\section{Procedimentos}

A pesquisa tem delineamento experimental com pré-teste e pós-testes.

No pré-teste, pós-teste 1 e pós-teste 2 , foram utilizadas as mesmas provas espaciais empregadas por Barnier (1989, 1994): projeção espacial e transformação espacial.

$\mathrm{Na}$ prova de projeção espacial (Anexo A) o examinador apresentava à criança uma folha contendo 12 desenhos (figuras humanas), em posições variadas. A criança deveria apontar o lado direito da figura humana, levando em conta a mudança de posição (em frente) em relação a seu próprio corpo.

$\mathrm{Na}$ prova de rotação e transformação espacial eram apresentados à criança seis cartões sucessivamente (Anexo B). Em cada cartão estavam distribuídas três figuras geométricas. $\mathrm{O}$ examinador mostrava o cartão-modelo à criança e apresentava um outro, no qual só estava colocada uma das figuras geométricas. A criança devia completá-lo colocando as outras duas figuras na mesma posição espacial do modelo.

O pós-teste 1 foi feito após 12 dias da realização do treino experimental e o pós-teste 2 após 22 dias. Foram utilizadas as mesmas provas, com pequenas modificações: na ordenação e cores na prova de projeção espacial e nas formas geométricas e cores na prova de transformação espacial, evitando-se assim a apresentação repetitiva do material.

Os resultados das crianças foram analisados atribuindo-se um ponto para o item acertado e zero para o item errado, em cada uma das duas provas. A criança poderia receber de zero (nenhum acerto) a 12 pontos (máximo de acertos permitido pela prova).

\section{Tarefa experimental.}

Antes da realização da tarefa experimental, as 20 crianças selecionadas para serem tutoras passaram por uma atividade prévia de tutoria junto às que seriam suas tutoradas na atividade experimental, com o objetivo de favorecer a interação entre elas. Nessa atividade a criança tutora orientava a criança tutorada a realizar uma dobradura, em uma das duas modalidades, explicação oral ou explicação oral com demonstração.

No experimento foi utilizado o jogo do parking, como em Barnier (1989). O jogo do parking é inspirado na prova das três montanhas, de Piaget e Inhelder (1948) e na prova da cidade (village) de Doise e Mugny (1981). Trata-se de uma atividade envolvendo orientações e relações espaciais que coloca problemas de realização que tornam possíveis explicações que dizem respeito ao entendimento da tarefa e procedimentos para solucioná-la. O material consiste em uma superfície quadrada de papelão, quatro carrinhos em miniatura, uma árvore e um boneco (guarda), conforme esquema no Anexo C.
No jogo do parking, o examinador montava previamente um estacionamento e o apresentava à criança tutora, que o usava como modelo para a atividade de tutoria. A criança tutorada recebia os mesmos materiais para montar o seu estacionamento e desenvolvia essa atividade orientada pela tutora.

Cada um dos grupos realizou a atividade em uma das três condições:

1. GE I (individualmente): o experimentador apresentava à criança o estacionamento-modelo e oferecia o material para que ela montasse o seu estacionamento.

2. GE II (tutoria oral): o experimentador apresentava à díade o estacionamento-modelo e oferecia o material à criança tutorada. A criança tutora deveria observar e ajudar a sua parceira na montagem do estacionamento, explicando-lhe oralmente como proceder.

3. GE III (tutoria oral com demonstração): o experimentador apresentava o estacionamento-modelo à díade e oferecia um jogo de material à criança tutora. Esta deveria usá-lo para explicar e para demonstrar à parceira como proceder. A criança tutorada recebia o material necessário para montar o seu próprio estacionamento.

No jogo do parking foram apresentadas quatro seqüências às crianças do GE I, GE II e GE III, para que fossem montadas as peças do estacionamento. A cada vez que o examinador apresentava o estacionamento-modelo, havia mudança da posição da porta de entrada, implicando em mudanças dos demais componentes do estacionamento. Na última seqüência foi acrescentado mais um carrinho, totalizando cinco carrinhos a serem dispostos no estacionamento.

As anotações do desempenho das crianças foram feitas em protocolo. Também foram feitas vídeogravações e anotações sob a forma de registro cursivo, por dois observadores, com o objetivo de permitir a análise das características das interações.

\section{Resultados}

O teste de Kolmogorov-Smirnov foi aplicado a cada um dos quatro grupos e seus resultados mostraram distribuições normais, o que permitiu que fosse utilizada a análise de variância para a comparação dos resultados.

A análise de variância (comparação múltipla de médias), para as duas provas do pré-teste (projeção espacial e transformação espacial) para amostras independentes, foi realizada com o objetivo de verificar se os quatro grupos a serem comparados poderiam ser considerados semelhantes quanto ao seu desempenho antes do experimento. Os resultados obtidos $(\mathrm{F}=0,14 \mathrm{e} \mathrm{p}=0,46$ para a prova de projeção espacial; $\mathrm{F}=0,77$ e $\mathrm{p}=0,27$ para a prova de transformação espacial), mostraram que não existiam diferenças significativas, aceitando-se portanto, que os grupos apresentaram desempenho equivalente nas provas do pré-teste.

As médias e resultados do teste de comparação de médias entre pré-teste, pós-teste 1 e pós-teste 2 para os quatro grupos, nas provas de projeção espacial e de transformação espacial, estão expressos na Tabela 1. 
Franciscato, I., \& Maluf, M.R. (2006). Efeitos de Duas Modalidades Tutoriais para a Criança Tutora em Tarefas Espaciais.

Tabela 1

Resultados do Teste de Médias para Amostras Dependentes, para os Quatro Grupos no Pré-teste, Pós-teste 1 e Pós-teste 2, nas Duas Provas Espaciais

\begin{tabular}{lllllll}
\hline & \multicolumn{5}{c}{ Projeção Espacial } & \multicolumn{2}{c}{ Transformação Espacial } \\
\cline { 2 - 7 } Grupos & Pré-Teste & Pós-Teste 1 & Pós-Teste 2 & Pré-Teste & Pós-Teste 1 & Pós-Teste 2 \\
\hline GEI & 6,4 & 6,4 & 5,5 & 5,8 & 5,4 & 5,3 \\
GEII & 6,3 & 8,0 & $8,7 *$ & 6,5 & 6,9 & 6,8 \\
GEIII & 6,7 & $8,4 *$ & $8,7 * *$ & 5,8 & $6,9 *$ & 6,3 \\
GC & 6,9 & 6,5 & 7,0 & 5,9 & 6,0 & $-5,0 * *$ \\
\hline
\end{tabular}

Nota. Comparações em relação ao pré-teste. ${ }^{*} \mathrm{p}<0,05 \quad * * * \mathrm{p}<0,01$

\section{Projeção Espacial}

Como se vê na Tabela 1, o teste de comparação de médias para amostras dependentes mostrou uma diferença estatisticamente significativa $(\mathrm{p}<0,02)$, indicativa do progresso das crianças tutoras do GE II (explicação oral) no pós-teste 2, em projeção espacial. O grupo de crianças tutoras do GE III (explicação oral com demonstração) mostrou avanços no pós-teste $1(\mathrm{p}<0,02)$ e no pós-teste 2 $(\mathrm{p}<0,01)$. No GE I (crianças que realizaram sozinhas a atividade) e no GC não foram observadas diferenças estatisticamente significativas.

Este resultado permite a aceitação da hipótese de que as crianças tutoras, que explicam para outra criança como resolver uma tarefa, obtêm maior progresso na noção de projeção espacial do que as crianças que fazem sozinhas a mesma atividade e do que as crianças que não passaram pela atividade experimental. Aceita-se, portanto, que a tutoria na modalidade explicação oral com demonstração gerou maiores benefícios para a criança tutora do que a tutoria apenas com explicação oral, no que diz respeito à aquisição de noções de projeção espacial.

\section{Transformação Espacial}

Nessa prova, como se vê na Tabela 1, só houve progresso estatisticamente significativo das crianças do GE III, ou seja, daquelas que exercitaram uma atividade de tutoria na condição de explicar oralmente e demonstrar na ação ( $\mathrm{p}<0,04$ no pós-teste 1$)$. A diferença significativa não se manteve no pós-teste 2 .

Esse resultado sugere a aceitação da hipótese de que a tutoria na modalidade explicação oral com demonstração traz maior benefício para a criança tutora, na aquisição da noção de transformação espacial, quando comparada à tutoria apenas com explicação oral ou à execução da tarefa sem interação com outra criança.

Embora os outros resultados do teste estatístico não tenham mostrado diferenças no nível de confiança aceito ( $p<0,05)$, o exame das médias permite não descartar a hipótese de que as crianças tutoras (GE II, tutoria com explicação oral e GE III, tutoria com explicação oral e demonstração) obtiveram maior progresso na noção de transformação espacial, quando comparadas às crianças que trabalharam sozinhas e às que não realizaram a atividade.

Essa conclusão é reforçada pela análise qualitativa dos progressos obtidos pelas crianças, verificando-se a traje- tória do desempenho das crianças tutoras (GE II, explicação oral; GE III, explicação oral com demonstração) no pré-teste, pós-teste 1 e pós-teste 2 . Os resultados mostraram que das 20 crianças tutoras, 13 obtiveram aumento de pontos nas duas provas (ao menos em um dos pós-testes) e sete obtiveram progresso ao menos em uma das provas, em um dos pós-testes.

Considerando-se os pontos obtidos nos pós-testes 1 e 2 , verificou-se que a modificação da pontuação nas duas provas não se configura numa ascendência contínua para os tutores do GE II e GE III. Foram observadas variações para mais e para menos na pontuação obtida, comparandose pré-teste e pós-testes, assim designadas: progresso contínuo (aumento de pontos no pré-teste 1 e esse aumento continua no pré-teste 2 ), progresso estável (aumento de mesmo número de pontos nos dois pós-testes), progresso irregular I (aumento no pós-teste 1, mas o número de pontos no pós-teste 2 é igual ou menor que no pós-teste1), progresso irregular II (queda no pós-teste 1 e aumento apenas no pós-teste 2 ) e progresso irregular III (pós-teste 1 igual ao pré-teste e aumento apenas no pós-teste 2 ).

\section{As Interações entre as Díades de Crianças}

A análise das seqüências interativas videogravadas e das anotações feitas pelo examinador durante as sessões de tutoria, permitiu a identificação de especificidades na interação dos tutores nas modalidades explicação oral e na explicação oral com demonstração.

Foram observadas trocas de olhares entre tutor e tutorado, gestos e sons com finalidade comunicativa utilizados pela criança tutora, tanto na modalidade explicação oral quanto na explicação oral com demonstração.

No uso da linguagem oral, o tutor fazia perguntas como "Onde você vai colocar?" ou "Você não acha que tem uma coisa diferente do seu?"; dizia palavras de incentivo como "Isso... vai indo" ou "Você pode começar a fazer"; ou ainda, expressava palavras que apontavam o equívoco do tutorado de forma bastante direta como “Tá errado, olha aqui!", em ambas as modalidades tutoriais.

Além dessas manifestações, explicações orais propriamente ditas foram observadas no tutor da modalidade explicação oral e no tutor da modalidade explicação oral com demonstração. Essas explicações eram de alcances diferentes: curtas, indicando procedimentos a serem seguidos pelos tutorados, como "Ó, você tem que olhar. Vê esse 
aqui, ó. Ele tá reto aqui", ou longas, em geral estabelecendo mais de uma relação espacial entre os objetos do modelo do jogo do parking, como "Ó, a sua árvore tá de frente pro seu guarda, não tá? Não precisa ser reto como esse. Se modificar um pouco, põe o carro na frente da árvore, mas como este aqui".

Explicações curtas apareceram nas duas modalidades tutoriais, porém, explicações mais longas foram utilizadas com maior freqüência pelos tutores do GE III. Considerando-se ainda explicações curtas e longas juntas, a freqüência de utilização de explicações pelo tutor junto ao tutorado foi mais freqüente no GE III (167 explicações) quando comparada à freqüência no GE II (113 explicações).

Algumas diferenças entre meninos e meninas se manifestaram nas interações tutoriais: no GE II (explicação oral), os meninos tutores corrigiram mais os seus parceiros do que as meninas; por outro lado, as meninas tutoradas fizeram mais perguntas do que os meninos. No GE III (explicação oral com demonstração) não foram observadas diferenças que pudessem estar relacionadas ao sexo.

\section{Discussão}

Os resultados mostraram que crianças tutoras obtiveram benefícios na aquisição das noções espaciais examinadas, na modalidade explicação oral e na modalidade explicação oral com demonstração. Verificou-se também que na modalidade explicação oral com demonstração os progressos foram maiores, o que nos sugere que a demonstração tem papel importante na aquisição das noções espaciais.

Na observação da tendência geral dos resultados, confirmou-se a direção para o progresso na aprendizagem da criança tutora, com vantagem para a tutora que explica e demonstra à tutorada como realizar as tarefas que envolvem noções de projeção ou transformações espaciais.

Os resultados deste estudo corroboraram os achados de Barnier (1989) no que diz respeito à superioridade da interação tutorial para o avanço das crianças em noções espaciais que requerem projeção da noção de direita e esquerda e projeção de objetos que guardam entre si relações espaciais. Observou-se também a tendência ao progresso no desempenho do GE I (crianças que realizaram sozinhas a atividade), tal como foi verificado no estudo de Barnier. Concordamos com Barnier quanto à explicação de que a ocorrência de algum progresso, para a criança que sozinha resolve a tarefa espacial, pode ser atribuída ao conflito cognitivo gerado pela ação ao realizar a tarefa. Porém, enquanto que para a criança que resolve a tarefa sozinha é mais difícil admitir outra perspectiva que não a sua própria, dada a ausência de um interlocutor, na díade interativa, dada a interação com o parceiro, a criança tutora é levada com mais facilidade a admitir a possibilidade da existência de outra perspectiva que não a sua. Acrescente-se à explicação que, mesmo que na avaliação do tutor a perspectiva do tutorado não seja a mais correta, ele terá de levá-la em conta para reorientar seu parceiro e ao fazer isso, o tutor precisa confrontá-la com a sua. Exemplo dessa ocorrência, em nosso estudo, foi o de uma tutora do GE II que, face à discordância da tutorada, insistia para que esta explicitasse as razões que a levavam a contrapor-se à sua orientação, provavelmente tentando apreender e compreender a lógica do outro em confronto com a sua própria.

Os resultados da presente pesquisa diferiram dos de Barnier $(1989,1994)$ quanto ao número de crianças que obtiveram benefícios da tutoria: enquanto que no trabalho de Barnier duas das doze tutoras que explicavam oralmente não obtiveram progresso algum, em nosso estudo todas as crianças obtiveram algum progresso (dez crianças da modalidade explicação oral e dez crianças da modalidade explicação oral com demonstração). Barnier também encontrou relação entre maior número de explicações orais dadas pelo tutor e maior progresso nas noções espaciais em dois dos doze tutores. Em nosso estudo não confirmamos essa relação no GE II (modalidade de tutoria com explicação oral), pois a tutora com maior freqüência de interação obteve progresso apenas em uma prova (projeção espacial). Porém essa relação foi confirmada no GE III (modalidade explicação oral com demonstração): o tutor com maior freqüência de interação oral e demonstração, obteve progresso nas duas provas espaciais. De todo modo, a cautela é bem-vinda frente a esse resultado, uma vez que outro tutor do mesmo grupo, que também apresentou alta freqüência de explicações, apenas obteve progresso em uma das provas (projeção espacial).

Barnier (1989) concluiu que a criança tutora, que interage com a parceira explicando-lhe oralmente como resolver a tarefa espacial, apóia-se na produção desta, para mentalmente elaborar sua própria solução. Nossos resultados sugeriram que, além do apoio visual na produção do outro, a utilização da demonstração permite ao tutor referir-se e apoiar-se em objetos concretos para operar manipulando-os. Por outro lado, a interação social entre parceiros, quando apoiada na demonstração, possibilitaria maiores benefícios para o tutor, quando comparada à interação social baseada apenas na linguagem oral voltada para a ajuda na realização da atividade.

Os resultados sugeriram uma certa hierarquia quanto ao benefício da interação tutorial para a aprendizagem das noções espaciais: entre tutoria com explicação oral e tutoria com explicação oral e demonstração, esta última parece produzir maiores benefícios. Entre realização solitária da tarefa e tutoria na modalidade explicação oral, a condição que mais favorece a aquisição das noções espaciais é esta última.

Comparando-se os efeitos da tutoria nas duas provas, os progressos das crianças tutoras, nas duas modalidades tutoriais, foram mais evidentes quando diziam respeito às noções espaciais de projeção de direita e esquerda (projeção espacial). Essa diferença nos benefícios cognitivos pode estar ligada às diferenças de dificuldade entre as provas utilizadas. A prova de projeção espacial solicita da criança a noção espacial de direita e esquerda sobre um objeto, tendo de fazer a rotação da noção de direita e esquerda 
que tem diante de si para identificá-la nas figuras humanas. No entanto, a prova de transformação espacial parece ser mais difícil, uma vez que solicita da criança a noção de relações espaciais entre vários objetos, o que demanda a rotação de três figuras geométricas ao mesmo tempo, sendo por essa razão, mais complexa.

Mesmo assim, quando a demonstração é adotada pelo tutor, é possível dizer que na prova mais complexa, a de transformação espacial, houve progresso cognitivo das crianças tutoras que orientaram suas parceiras valendose da explicação oral e da demonstração, pois das dez crianças tutoras que exercitaram essa modalidade de tutoria, todas tiveram algum aumento na pontuação, ao menos em um dos pós-testes dessa prova.

Observando-se as orientações dadas pelas crianças tutoras na modalidade explicação oral com demonstração, três delas orientaram suas parceiras acertadamente nas quatro seqüências do jogo do parking e obtiveram diferentes tipos de progresso: contínuo/estável, contínuo/ irregular I e irregular I/irregular I, respectivamente nas provas de projeção espacial e transformação espacial. Por outro lado, outras três tutoras orientaram erroneamente suas parceiras nas quatro seqüências do jogo e também obtiveram diferentes tipos de progresso: contínuo/irregular, irregular/irregular e irregular/irregular. Esses resultados sugerem que embora a demonstração tenha papel importante na aprendizagem de noções espaciais mais complexas, é possível que em crianças mais desenvolvidas, os progressos sejam ainda maiores, conforme já sugeria Damon (1984) sobre benefícios da tutoria para o tutor. Segundo ele, quanto mais sabe o tutor, maior o benefício da tutoria, porém quando este se encontra menos desenvolvido, progressos menores ocorrem, pois mesmo na condição de domínio mais restrito de um dado conhecimento, a necessidade de ampliá-lo também traz alguma contribuição ao tutor.

No que se refere à necessidade de competência mínima, os resultados desta pesquisa sugerem que essa condição se aplica à interação tutorial, como vimos. Contudo, é preciso assinalar que ela não elimina a possibilidade de que a tutoria seja desempenhada por crianças com dificuldades de natureza cognitiva ou comportamental. Mostraram-se favoráveis a essa hipótese os resultados de Custer e Osguthorpe (1983) e Maher (1984), com a recomendação de que se observe a escolha de área de atividade em que o tutor se mostre competente.

Foram verificados comportamentos comuns aos tutores nas duas modalidades tutoriais, como a ocorrência do tempo de espera frente ao tutorado: os tutores mostraram-se capazes de levar em conta o tempo necessário que o parceiro parecia necessitar para resolver a tarefa, interferindo em seguida, ao mesmo tempo em que acompanhavam e avaliavam a realização da tarefa pelo tutorado, parecendo reorganizar o que deveria ser feito, fosse na continuidade ou na correção da performance do tutorado. Esse tempo de espera ocorria tanto no início da atividade tutorial quanto intercalado aos episódios interativos entre tutor e tutorado.
Nas duas modalidades tutoriais, formas complementares à linguagem oral, como sons, gestos indicativos com o dedo indicador, gestos com a cabeça e rotação de corpo, além da troca de olhares, apareceram quando conversavam e manipulavam as peças nas pranchas do jogo do parking. Os tutores se valeram de correções diretas na orientação dos tutorados, mas também utilizaram perguntas, lembrando a maiêutica socrática, em que estas são consideradas instrumento do mais sábio para levar o outro a tomar consciência da insuficiência de suas respostas, na tentativa de chamar a atenção para aspectos da resolução da tarefa espacial que ainda não haviam sido observados pelos tutorados. Todos os tutores dos dois grupos lançaram perguntas a seus tutorados como forma de orientá-los na realização da tarefa espacial. Contudo, foi no Grupo III, modalidade explicação oral com demonstração, que se concentrou o maior número de perguntas dos tutores aos tutorados.

Os tutores das duas modalidades valeram-se também de explicações que variaram em complexidade: mais curtas, em que o tutor orientava o procedimento de modo direto, e mais complexas, em que o tutor procurava chamar a atenção do tutorado para a observação das relações espaciais que as peças do jogo do parking conservavam entre si. Explicações curtas ocorreram nos dois grupos tutoriais, mas no GE III explicações mais detalhadas surgiram com maior freqüência. Resultados apontando diferenças nas explicações de alunos que orientam a outros foram referidos também por Webb (1991).

Quanto a uma possível relação entre freqüência de interações e progressos obtidos na aprendizagem das noções espaciais, já apontada na análise dos resultados, a formulação de Moro (1991) a respeito da diferenciação entre, de um lado a participação mais ou menos intensa na tarefa, e de outro a solução mais ou menos adiantada para a tarefa, também parece apropriada ao que foi observado nos dois grupos de tutores desta pesquisa: não é o número de interações o fator decisivo para o progresso, mas a interação empreendida como melhor solução da tarefa, desencadeada pela necessidade de orientação ao parceiro, que parece explicar os benefícios cognitivos obtidos.

Algumas diferenças atribuídas ao sexo dos tutores foram encontradas. Guardado o cuidado de que essa manifestação não apareceu em todos os tutores, observou-se ligeira predominância do sexo masculino sobre o feminino, na correção direta, mas tutoras fizeram mais perguntas do que tutores aos tutorados, como forma de orientação aos parceiros. Também em relação ao número de explicações fornecidas ao tutorado, o sexo feminino predominou em relação ao masculino. Nos limites desta pesquisa, essa diferença lembra alguns estudos filiados a outro quadro teórico-metodológico, a psicoetologia, em que se encontra referência a diferenças de sexo no compor tamento de cuidado, com predominância no sexo feminino (Carvalho, 1996).

Os resultados desta pesquisa também devem ser considerados à luz do grau de conhecimento entre as díades que interagem como tutor e tutorado na realização da tarefa experimental. Neste estudo, tivemos a preocupação 
de garantir um certo grau de conhecimento prévio entre as crianças das díades, fazendo com que realizassem juntas uma atividade antes do experimento. Porém, apesar dessa aproximação, verificou-se que em algumas díades, alguns tutores pouco interagiram na situação experimental. Indagamos se os progressos dos tutores teriam sido diferentes se o grau de familiaridade entre tutores e tutorados fosse ainda maior do que o possibilitado por aquela atividade.

Sobre essa variável, grau de conhecimento entre parceiros como fator de influência em estudos tutoriais, autores como Custer e Osguthorpe (1983) constataram aumento de interações (de 5\% no início do experimento para $46 \%$ no final) e de aceitação social entre crianças tutoras e suas tutoradas, na medida em que houve maior tempo de convivência entre elas.

O fortalecimento das interações entre crianças, decorrente de maior tempo de convivência, também é referido por Emmel (1990) em estudo em que foram previstos vários encontros dos sujeitos. Por outro lado, outros pesquisadores observaram que, quando as crianças se conhecem bem, surgem aspectos constituintes da interação nem sempre favoráveis. Góes (1995), por exemplo, admite que entre pares conhecidos ocorre avaliação da capacidade de uma criança pela outra de modo constante, seja a interação de caráter instrutivo ou não e, também, que parceiros determinam uns aos outros o lugar de cada um na rede de relações pessoais, concedendo ou negando lugares de prestígio. Burk (1996) admite que a amizade desempenha papel importante na interação social, mas não é o determinante único para sua ocorrência. Frente a essas indagações sobre o grau de conhecimento entre as díades e sua relação com os progressos obtidos pelas crianças tutoras, apropriamo-nos da recomendação de Burk quanto à necessidade de outras pesquisas sobre a influência da amizade nas interações.

\section{Considerações Finais}

As possíveis implicações dos resultados das pesquisas que tratam das interações entre crianças para a aprendizagem e desenvolvimento ainda não estão suficientemente consolidadas (Seidl de Moura, 1998) no campo educacional e o mesmo parece acontecer com a tutoria, embora sua raiz epistemológica seja bastante antiga. Por essa razão são tecidas a seguir algumas considerações, resultantes desta pesquisa, que consideramos importantes para o campo pedagógico.

A tutoria pode ser importante estratégia para promover avanços e progressos cognitivos, bem como fortalecer a auto-estima dos alunos em diferentes situações em sala de aula. Ela pode coexistir com a realização individual de tarefas pedagógicas, já que não só traz vantagens para o tutorado, por aprender com um parceiro mais capaz, como também para o tutor, por aprender ainda mais aquilo que empreende como conteúdo de ensino ao parceiro. Especialmente em relação à explicação oral com demonstração, vale lembrar atividades pedagógicas como resolução de operações aritméticas básicas, resolução de problemas geométricos ou de representações cartográficas, experimentos na área de ciências e atividades plásticas, em que a demonstração acompanha a explicação oral.

Pode ainda a tutoria responder à condição de heterogeneidade dos alunos em relação ao processo de alfabetização na língua materna, se adotada sistematicamente como forma de troca entre os alunos mais e menos adiantados, com benefícios não só para tutorados, mas também para tutores, contribuindo para a superação de problemas relativos à alfabetização, nas séries escolares iniciais. Como refere Amaral (2001), crianças brasileiras com dois a três anos de insucesso escolar submetidas a programa especial de suplementação para melhoria do desempenho escolar, permanecem com marcas negativas na auto-imagem, decorrentes do fracasso escolar anteriormente experimentado. Nesse sentido, a tutoria colabora preventivamente, evitando fracassos e fortalecendo a auto-estima do aluno, desencadeando o denominado efeito "bola-de-neve" já demonstrado nos estudos de Lippitt (1976) e Gartner, Kohler e Riesman (1971), em que a aquisição da autoconfiança impulsiona a aquisição de novos conhecimentos e estes, por sua vez, retornam ao tutor em forma de maior auto-estima.

No atendimento educacional de alunos com necessidades especiais, a tutoria pode proporcionar-lhes benefícios não só como tutorados, mas também como tutores, desde que se garantam algumas habilidades ou conhecimentos mínimos sobre um dado assunto. Ressalta-se que para crianças com limitações cognitivas, na condição de tutorado ou de tutor, a modalidade em que a demonstração acompanha a explicação oral mostra-se como potente recurso no auxílio de lacunas da linguagem oral e apoio concreto para a aprendizagem dos conteúdos escolares mais abstratos.

Lembrando que necessidades especiais não se referem apenas a dificuldades, mas também a talento ou capacidade superior em algumas habilidades (Alencar, 1986), alunos talentosos que tomam o lugar de tutores podem retirar dessa condição benefícios pessoais, desenvolvendo ainda mais as habilidades em que se sobressaem. No atendimento educacional desses alunos, a tutoria pode acontecer tanto intra-sala, em horário normal, como intersalas, em horário alternado, através de programas, como Clubes da Matemática, Clube das Ciências, Oficina de Artes, Oficina de Leitura, alternativas ainda pouco exploradas nas escolas brasileiras. Vantagens em habilidades ou conhecimento poderiam ser mais aproveitadas desde o ensino básico, principalmente em atividades em que a demonstração seja condição necessária.

Finalizando, cabe lembrar que a tutoria, enquanto estratégia educacional promotora de aprendizagem para tutorados e tutores, pode ser adotada não só nos segmentos iniciais de escolaridade como também em segmentos mais adiantados, inclusive em cursos superiores de graduação. 
Franciscato, I., \& Maluf, M.R. (2006). Efeitos de Duas Modalidades Tutoriais para a Criança Tutora em Tarefas Espaciais.

\section{Referências}

Alencar, E. S. (1986). Psicologia e educação do superdotado. São Paulo, SP: EPU.

Amaral, S. A. (2001). A imagem de si em crianças com histórico de fracasso escolar à luz da teoria de Henri Wallon. Tese de Doutorado não-publicada, Curso de Pós-Graduação em Psicologia da Educação, Pontifícia Universidade Católica de São Paulo, SP.

Baldi, E. M. B. (2000). A tutoria segundo o corpo discente e a dinâmica da mediação adotada no Instituto de Formação de Professores Presidente Kennedy. Tese de Doutorado não-publicada, Programa de Pós-Graduação em Educação, Universidade Federal do Rio Grande do Norte, Natal, RN.

Balacheff, N. (1982). Preuve et démonstration en mathématique au collège. Recherches en Didactique des Mathématiques, 33, 261304

Barnier, G. (1989). L'effet-tuteur dans des situation mettant en jeu des rapports spatiaux chez des enfants de $7-8$ ans en interactions diadiques avec des pairs de 6-7 ans. European Journal of Psychology of Education, 4(3), 385-399.

Barnier, G. (1994). L'effet-tuteur dans une tâche spatiale chez des enfants d'âge scolaire. Thèse de Doctorat, Université de Provence, France.

Berzin, C. (1999). Effet de la position de partenaire le plus compétent dans la résolution en dyade faiblement assymétrique d'une tâche de classification. Psychologie et Éducation, 37, 29-42.

Burk, D. I. (1996). Understanding friendship and social interaction. Childhood Education. 72(5), 282-285.

Button, B. L., Sims, R., \& White, L. (1990). Experience of proctoring over three years at Nottingham Polytechnic. In $\mathrm{S}$. Goodlad \& B. Hirst (Eds.), Explorations in peer tutoring (pp. 98-109). Oxford, UK: Blackell.

Carvalho, A. M. (1996). Comportamento de cuidado entre crianças: Um estudo longitudinal em diferentes ambientes institucionais. Tese de Doutorado não-publicada, Curso de Pós-Graduação em Psicologia Experimental, Universidade de São Paulo, SP.

Custer, J. D., \& Osguthorpe, R. T. (1983). Improving social acceptance by training handicapped students to tutor their nonhandicapped peers. Exceptional Children, 50 (2), 175-189.

Damon, W. (1984). Peer education: The untapped potential Journal of Applied Developmental Psychology, 5, 331-343.

Doise, W., \& Mugny, G. (1981). Le Développement Social de l'Intelligence. Paris: InterEditions.

Emmel, M. L. G. (1990). Interação Social: A função da atividade. Tese de Doutorado não-publicada, Curso de Pós-Graduação em Psicologia, Universidade de São Paulo, SP.

Fenrick, N. J., \& Peterson, T. K. (1984). Developing positive changes in attitudes towards moderately/severely handicapped students through a peer tutoring program. Education and Training of Mentally Retarded, 19 (2), 83-90.

Filippaki, N., Barnier, G., \& Papamichaël, Y. (2001). L'effet bénéfique du rôle de tuteur chez des enfants d'âge préscolaire confrontés à la réalisation d'un damier. Psychologie et Éducation, $44,27-42$.

Finkelsztein, D., \& Ducros, P. (1989). Un dispositif de lutte contre l'échec scolaire: L'enseignement par élèves-tuteurs. Revue Française de Pédagogie, 88, 15-26.

Gandon-Cretois, E. (2001). Étude de l'effet-tuteur chez des enfants d'âge préscolaire dans des tâches de catégorisation. Thèse de Doctorat, Université de Haute Bretagne Rennes2, Rennes, France.
Gartner, A., Kohler, M. C., \& Riessmann, F. (1971). Children Teach Children: Learning by Teaching: New York: Harper and Row.

Góes, M. C. R. (1995). A construção do conhecimento. Examinando o papel do outro nos processos de significação. Temas em Psicologia, 2, 23-29.

Goodlad, S., \& Hirst, B. (1989). Peer tutoring: A guide to learning by teaching. London: Kogan Page.

Hartup, W. W. (1983). Peer relations. In E. M. Hetherington (Ed.) \& P. H. Mussen (Series Ed.), Handbook of Child Psychology (Vol. IV, p. 102-177). New York: John Willey \& Sons.

Jones, J. (1988). Paired reading with mentally handicapped adults Paired Reading Bulletin, 4, 78-81.

Lippitt, P. (1976). Learning through cross-age helping: why and how. In V. L. Allen (Ed.), Children as teachers, theory and research on tutoring (pp. 157-168). New York: Academic Press

Maher, C. A. (1984). Handicapped adolescents as cross-age tutors: Program, description and evaluation. Exceptional Children, 51, 56-63

Moro, M. L. F. (1991). Crianças com crianças aprendendo: Interação social e construção cognitiva._Cadernos de Pesquisa, $79,31-43$

Nemirovsky, A. (1992). El aprendizage del lenguaje escrita a través de la interacción. Textos, 17, 55-65.

Oliveira, Z. de M. R., \& Rossetti-Ferreira, M. (1993). O valor da interação criança-criança em creches no desenvolvimento infantil. Cadernos de Pesquisa, 87. 62-70.

Perret-Clermont, A. N. (1978). A construção da inteligência pela interação social. Lisboa, Portugal: Socicultur.

Piaget, J., \& Inhelder, B. (1948). La représentation de l'espace chez l'enfant. Paris: PUF.

Seidl de Moura, M. L. (1998). Cooperação, aprendizagem e desenvolvimento no ambiente escolar. Mente Social, 4.(1), 9-32.

Shafer, M. S., Egel, A. L., \& Neef, N. A. (1984). Training mildly handicapped peers to facilitate changes in school interaction skills of autistic children. Journal of Applied Behaviour Analysis, 17(4), 461-476.

Verba, M. (1996). Constructivism and the co-construction of knowledge in young children [Abstract]. In University of Geneva (Ed.), The Growing Mind Congress. Book of Abstracts (pp. 17). Geneva, Italy: University of Geneva.

Webb, N. M. (1991). Task-related verbal interation and mathematics learning in small groups. Journal for Research in Mathematics Education, 22 (5), 366-386.

Winnykamen, F. (1997). Imitation interactive et interactions tutorielles. Quelques remarques. Bulletin de Psychologie, 427, 63-69.

Winnykamen, F. (1998). Approche psychologique de la tutelle. In A. Dumas-Carré \& A. Weil-Barais (Eds.), Tutelle et médiation dans l'éducation scientifique (pp. 29-58). Paris: Peter Lang 

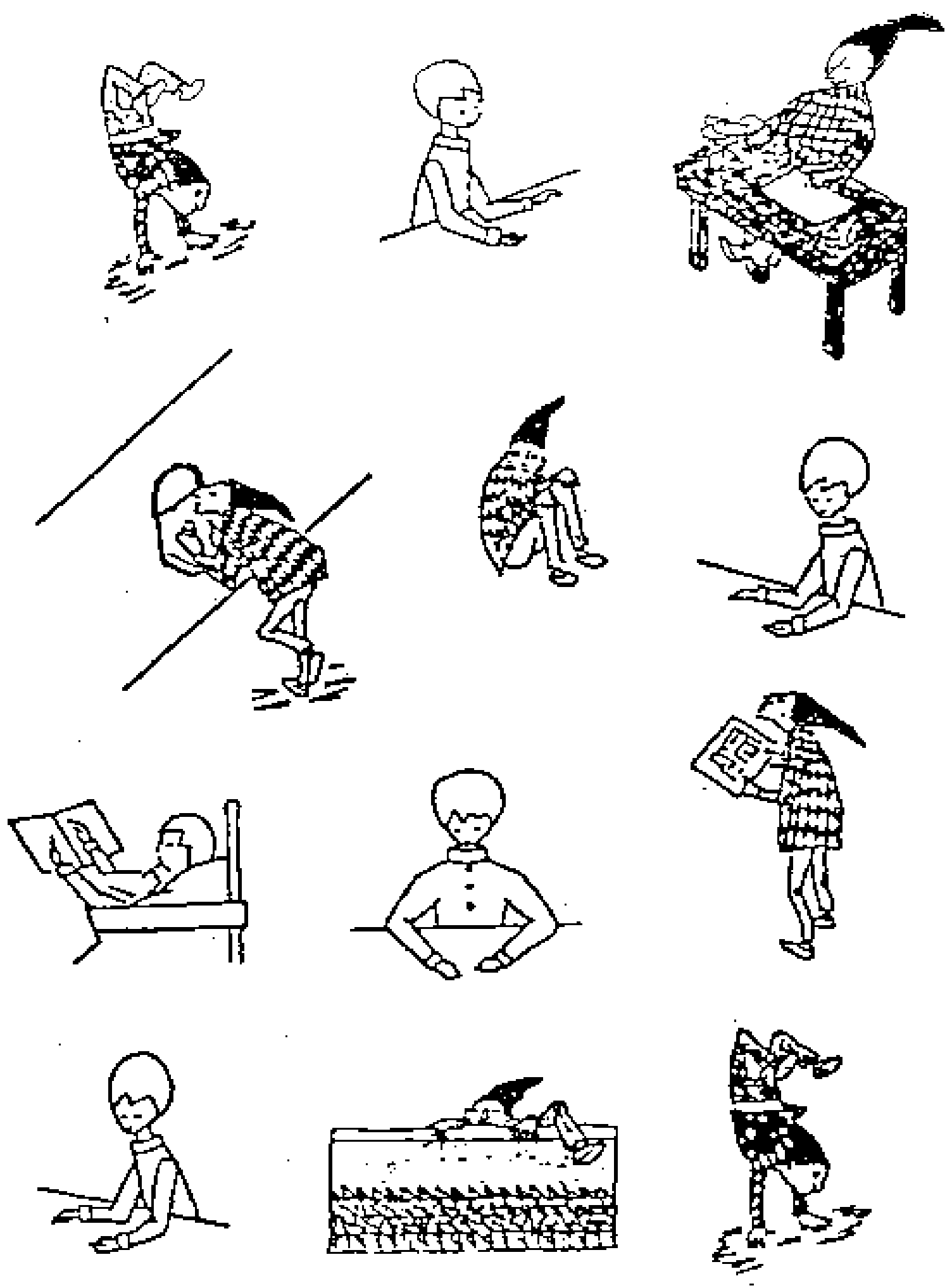
Franciscato, I., \& Maluf, M.R. (2006). Efeitos de Duas Modalidades Tutoriais para a Criança Tutora em Tarefas Espaciais.

Anexo B

Prova de Transformação Espacial

1
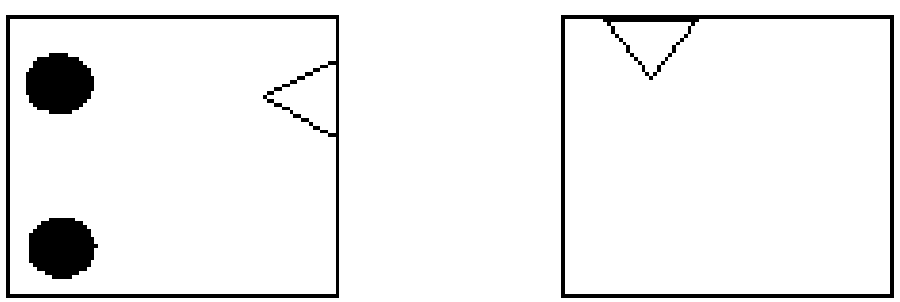

2
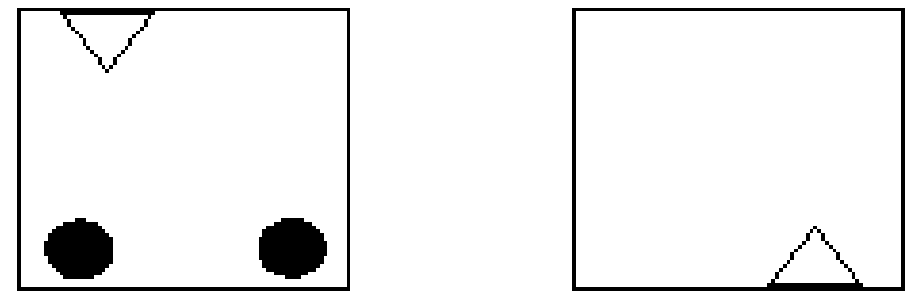

3
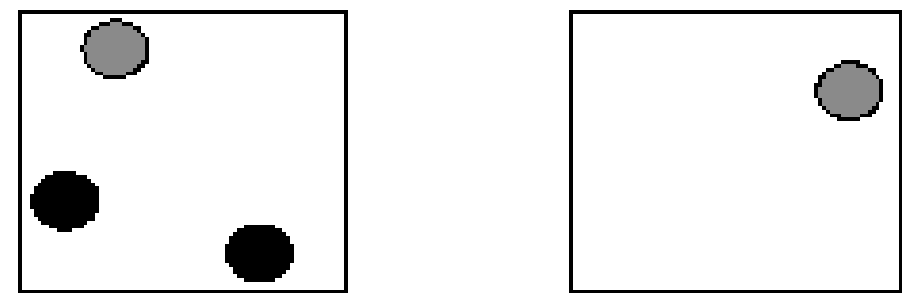

4
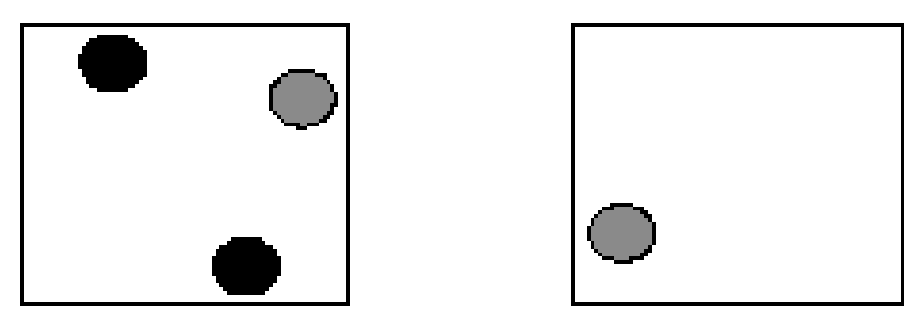

5
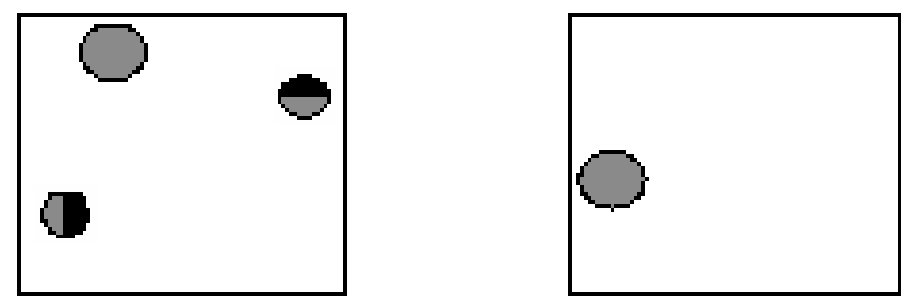

6
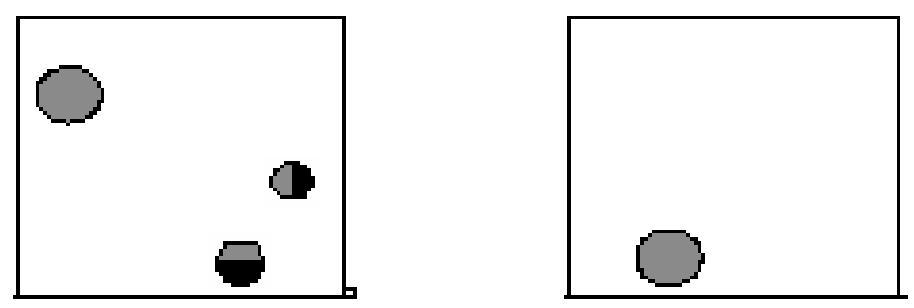


\section{Anexo C}

Experimento: Jogo do parking

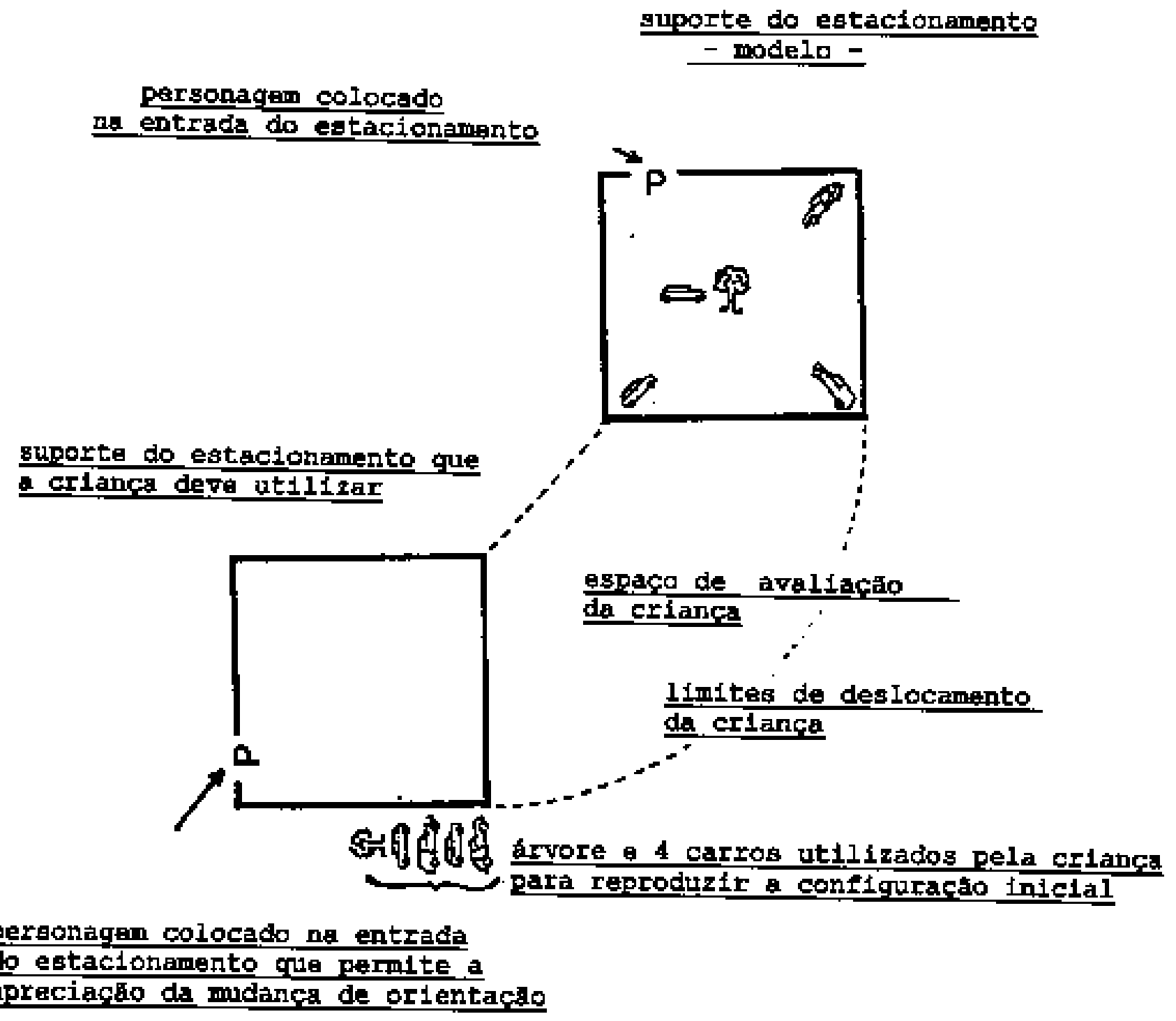

